\title{
A New Species of Sinojackia (Styracaceae) from Hubei, Central China
}

\author{
Yao Xiao-Hong, 'Ye Yi-Gang, ', Ge Ji-Wen, ${ }^{2}$ Kang Ming, ${ }^{1}$ and Huang Hong-wen ${ }^{1}$-*
}

'Wuhan Botanical Garden, Chinese Academy of Sciences, Wuhan 430074, People's Republic of China.

*Corresponding author: hongwen@wbgeas.cn

${ }^{2}$ Faculty of Life Sciences and Technology, School of Environmental Studies, China University of Geosciences, Wuhan 430074, People's Republic of China

Aвsтract. Sinojactia huangmeiensis J. W. Ge \& X. H. Yao, a new species of Sinojactia Hu from Hubei Province, central China, is described and illustrated. It is similar to S. xylocarpa Hu. The new species differs from S. xylocarpa, however, in its smaller flowers with broadly ovate petals and smaller fruit bearing a papillate short beak.

Key words: China, Sinojactia, Styracaceae.

Sinojactia $\mathrm{Hu}$ is a Chinese endemic genus of only seven species (including the new one described here). The first report of this genus was based on a specimen from Jiangsu Province, in eastern China, which was recognized as S. xylocarpa Hu (Hu, 1929). Since then. Hu (1930) described $S$. rehderiana Hu from Jiangxi, and Merrill (1937) transferred Pterostyrax henryi Dummer to S. henryi (Dummer) Merrill. Subsequently, Luo (1992) described S. sarcocarpa L. Q. Luo from Sichuan, and Chen discovered S. microcarpa C. T. Chen \& G. Y. Li and S. oblongicarpa C. T. Chen \& T. R. Cao from Zhejiang and Hunan, respectively (Chen \& Li, 1997; Chen, 1998). Sinojactia oblongicarpa has also been treated as a synonym of $S$. sarcocarpa (Luo, 2005). During recent field surveys on the Longgan Lake Wetland Reserve located at the boundary between Hubei and Anhui Province, a new species of Sinojactia exhibiting distinctive morphological characters differing from other species of this genus was discovered.

Sinojackia huangmeiensis J. W. Ge \& X. H. Yao. sp. nov. TYPE: China. Hubei: Huangmei County. Xiaxin, Qianlin, bushes by Longgan lake. $30 \mathrm{~m}$. ca. $29.59^{\prime} \mathrm{N}, 11601 \mathrm{I}^{\prime} \mathrm{E}, 16 \mathrm{Apr} .2005$, X. H. Yao \& C. T. Chen 0.5003 (holotype, PE: isotype, HIB). Figure 1.

Haec species Sinojatiae xylocarpae affinis, sed floribus minoribus, petalis late-ovatis $10-12 \times 9-10 \mathrm{~mm}$. el fructibus minoribus, cum rostro papillato brevi $16-18 \mathrm{~mm}$ longo, 9-12 mm diam. differt.

Trees deciduous, to 3-4 $\mathrm{m}$ lall; trunk thomy, to $10 \mathrm{~cm} \mathrm{DBH}$; bark vertically fissured and peeling: branches grayish brown; current year's shoots green. densely stellate-pubescent, second year's branches blackish brown, glabrous, longitudinally striate: winter buds naked, with densely dark brown stellate trichomes. Leaves simple, altenate, papery; petiole 2-3 $\mathrm{mm}$; leaves at base of the flowering branch with blade ovate, other leaves with blade widely ovate to narrowly ovate, all leaves 5-12 × 2-6 cm: apex acuminate, margin serrate, secondary veins 8 to 10 per side; leaves sparsely stellate-pubescent abaxially and along veins adaxially, glabrescent. Inflorescences racemose, 4- to 6-flowered; pedicel 2-2.5 cm; sparsely stellate-puberulent, pendulous: calyx (5)6(7)-dentate: teeth triangular, $1-1.2 \times 0.9-1.2 \mathrm{~mm}$ at base. densely stellate-pubescent; corolla white, deeply 5- to 7-parted; lobes imbricate, broadly ovate, $10-12 \times 9$ $10 \mathrm{~mm}$, apex slightly cuspidate: stamens 10 to 12 . inserted at base of corolla, longer than corolla lobes: filaments erect, ca. $3.5-4 \mathrm{~mm}$. sparsely stellatepubescent: anthers oblong, comneclive shortly developed; ovary inferior, 3-locular, with 6 to 8 ovules per locule in 2 rows; placentation axile; style filiform, subulate. ca. 7-8 mm; stigma usually obscurely 3lobed. Fruit ovoid including a short and papillate beak, grayish brown. 16-18 × 9-12 mm diam.: beak 3-4 mm; exocarp ca. $1 \mathrm{~mm}$ thick, densely lenticellate: mesocarp spongy, ca. $4 \mathrm{~mm}$ thick: endocarp woody; seeds I to 2; seed coat smooth: endosperm fleshy.

Phenology. Flowering March through April; fruit ripening October through November.

Distribution and habitat. Only known from its type locality in Hubei, the new species grows on a hillside near Longgan lake together with Quercus serrala Thunberg var. trevipetiolala Nakai, Ilex cornuta lindley \& Paxton, Cephalotaxus fortunei Hooker, Liquidambar formosana Hance, and Symplocos paniculata (Thumberg) Miquel. This habitat differs from that of other Sinojackia, which favor riparian habitats.

Conservation status. Sinojactia huangmeiensis is endemic to China and known only from a single

Novon 17: 138-140. Publishet) on 23 April. 2007. 


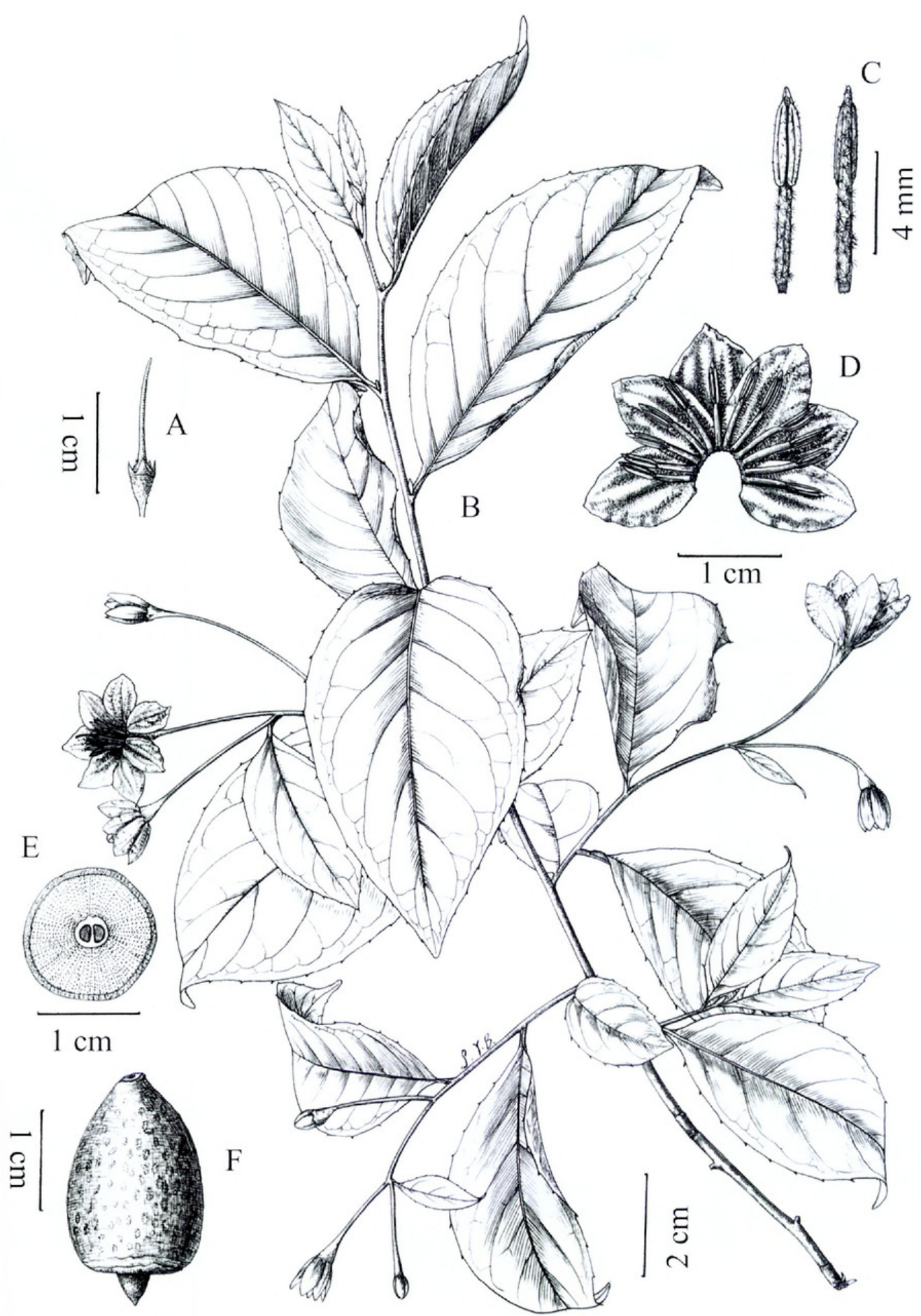

Figure 1. Sinojachia huangmeiensis J. W. Ge \& X. H. Yao. - A. Pistil. -B. Habit. - C. Stamens. -D. Opened calyx showing androecium. - E. Cross section of fruit. - F. Fruit. Drawn from the holotype X. H. Yao \& C. T. Chen 05003 (PE).

population of about 200 individuals (including young trees). A conservation strategy should be urgently carried out to conserve this rare, or probably endangered species, although extensive field survey for additional populations of the genus is needed to clarify the taxonomic and conservation status of the whole genus.

Sinojackia huangmeiensis is similar to $S$. xylocarpa but differs from it by its smaller flowers $(10-12 \times$ $9-10 \mathrm{~mm}$ ) with broadly ovate petals, while $S$. xylocarpa has larger flowers $(12-13 \times 8-10 \mathrm{~mm})$ with oblong-elliptic corolla lobes, as well as by its smaller grayish brown fruits $(16-18 \times 9-12 \mathrm{~mm})$ with a papillate short beak, while $S$. xylocarpa has larger rufous fruits $(20-25 \times 20-24 \mathrm{~mm})$ with a long and conical beak.

Paratypes. CHINA. Hubei: Huangmei County, bushes by Longgan lake, alt. 30 m, 18 Aug. 2001, J. W. Ge 200101 (CUG); alt. 30 m, 25 May 2004, X. H. Yao 04004 (HIB). 


\section{KEY TO THE: SPECHS OH SMOJACK}

la. Fruits glabrous.

2a. Fruils crimped after drying ...... S. sarcocarpa

2b. Fruils plump after drying.

3a. Fruits 6- 10 12-ribbed when dry: mesocarps undeveloped. . . . . . . S. microcarpa

3b. Fruits unribled when dry: mesocarps developed.

4a. Fruits with a papillate short beak: petals broadly ovate. . S. huangmeiensis

4h. Fruits with a long and conical or acuminate apical beak: petals oblong-elliplic.

5a. Fruits ovoid with a conical apical beak, $20-25 \times 20$ $24 \mathrm{~mm}$........... s. xylocarpa

5 b. Fruits ellipsoid with an acumi nate apical beak, 20-25 $\times$ $10-12 \mathrm{~mm} \ldots . .$. S. rehderian,

1b. Fruits stellate hairy ............ S. henrs

Acknowledgments. The authors are grateful to Chen Tao, Peter W. Fritsch, Kingsley Dixon, and an anonymous reviewer for their critical comments on the manuscripl, and to Sun Ying-Bao for his fine illustration of Sinojactia huangmeiensis. We also acknowledge Oi Cheng-Jing. Li Xiao-Dong, and Li
Xin-Wei for their enthusiastic help and encouragement. The work was supported in part by the Natural Scientific Foundation of China (30370153) and the Key Project of the Chinese Academy of Sciences (KSCX2-SW-104) and WZ No. 050809 of the Conservation Genetics Laboratorv. Wuhan Botanical Garden, Chinese Academy of Sciences.

literature Cited

Chen, C. T. 1995. Changiostyrax, a new genus of Stvracaceae from China. Guihaia 15: 289-292.

1998. A new species of Sinojactia Hu (Styracaceae from Hunan. south China. Edinburgh J. Bot. 5.5: 23.5-238. $\&$ G. Y. I.i. 1997. A new species of Sinojackia H, (Styracaceae) from Zhejiang, east China. Novon 7: 350-352. Hu. H. H. 1928. Sinojactia, a new genus of Stracaceae from southeastem China. Contr. Biol. Lab. Sci. Soc. China 4: $1-1$.

1930. Votulae systematicae ad floram sinensem, II. J. Arnold Arbor. 1 I: 224-228.

I.uo, I.. Q. 1992. A new species of Sinojackia from Sichuan. Acta Sci. Nat. Univ. Sunyalsenia 31: 78-79.

2005. A new synonym in the genus Sinojackia (Styracaceae). Acta Phytotax. Sin. 43: 561-564.

Merrill, E. D. 1937. Miscellanea sinensia. Sunyatsenia 3: $246-262$. 


\section{$2 \mathrm{BHL}$ Biodiversity Heritage Library}

Yao, Xiao-Hong. et al. 2007. "A New Species of Sinojackia (Styracaceae) from Hubei, Central China." Novon a journal of botanical nomenclature from the Missouri Botanical Garden 17, 138-140.

View This Item Online: https://www.biodiversitylibrary.org/item/41805

Permalink: https://www.biodiversitylibrary.org/partpdf/121745

\section{Holding Institution}

Missouri Botanical Garden, Peter H. Raven Library

\section{Sponsored by}

Missouri Botanical Garden

\section{Copyright \& Reuse}

Copyright Status: In copyright. Digitized with the permission of the rights holder.

License: http://creativecommons.org/licenses/by-nc-sa/3.0/

Rights: https://biodiversitylibrary.org/permissions

This document was created from content at the Biodiversity Heritage Library, the world's largest open access digital library for biodiversity literature and archives. Visit BHL at https://www.biodiversitylibrary.org. 